\title{
AVALIAÇÃo DO COMPORTAMENTO DE PASTA DE ALHO DURANTE O ARMAZENAMENTO (Allium sativum L.) ${ }^{1}$
}

\author{
Shirley Aparecida Garcia BERBARI ${ }^{2, *}$, Neliane Ferraz de Arruda SILVEIRA ${ }^{3}$,
}

\author{
Líria Akemi Tavares de OLIVEIRA ${ }^{2}$
}

\begin{abstract}
RESUMO
Este trabalho de pesquisa teve por objetivo avaliar o comportamento da pasta de alho sem adição de sal, por um período de três meses A principal perda de qualidade da pasta de alho é causada pelo escurecimento do produto que ocorre devido à ação de enzimas polifenoloxidases. Para controlar este escurecimento foi utilizado o ácido cítrico. O processamento da pasta de alho compreendeu as etapas: tratamento de imersão, descascamento, obtenção da pasta em "cutter", adição de ácido cítrico e sorbato de potássio para evitar o desenvolvimento de microrganismos deterioradores, acondicionamento em potes de plástico e de vidro, desaeração parcial em câmara de vácuo e armazenamento a temperatura ambiente. O produto final foi submetido a análises microbiológicas, físicas, para avaliação da cor e sensoriais, para avaliação da cor e do aroma. Os resultados da curva de acidificação mostraram que para abaixar o pH inicial da matéria-prima para 4,0 foram necessários $2,1 \mathrm{~g}$ de ácido citrico/100g de alho. Do ponto de vista microbiológico, a pasta de alho mantevese estável durante o periodo de armazenamento, apresentando contagens < $10 \mathrm{UFC} / \mathrm{g}$ para bactérias lácticas e < $10^{2} \mathrm{UFC} / \mathrm{g}$ para bolores e leveduras. As determinações fisicas e sensoriais de cor apresentaram resultados coincidentes e embora tenha ocorrido escurecimento, o produto se manteve em condições adequadas por três meses. Quanto ao aroma do produto, houve perda do odor característico, porém não foi detectada diferença significativa entre os dois tipos de embalagens utilizadas.

Palavras-chave: alho; pasta; ácido cítrico; vidro; plástico.
\end{abstract}

\section{SUMMARY}

EVALUATION OF THE SHELF LIFE OF GARLIC PASTE PACKED INTO PLASTIC AND GLASS CONTAINERS. The objective of this study was to evaluate the behavior of unsalted garlic paste during a three months period. The main cause of quality loss in garlic paste is a darkening of the product due to the action of poliphenolases enzymes. Citric acid was used to control this darkening. Processing of the garlic paste comprised the following steps: immersion treatment, peeling, reduction to paste in a cutter, addition of citric acid and potassium sorbate to avoid the development of deteriorative microorganisms, packing into plastic pots and glass jars, partial de-aeration in a vacuum chamber and storage at room temperature. The final product was submitted to microbiological analyses, physical evaluation of the color and sensory evaluation of color and aroma. The acidification curve showed that it was necessary to add $2.1 \mathrm{~g}$ of citric acid per $100 \mathrm{~g}$ of garlic to lower the initial $\mathrm{pH}$ value to 4.0. The garlic paste remained microbiologically stable during the storage period. The physical and sensory analyses of color matched, and although darkening occurred, the product remained adequate for three months. There was a loss of the characteristic odor, but no differences were detected between the two types of package.

Keywords: garlic; paste; citric acid; glass; plastic.

\section{1 - INTRODUÇÃO}

A busca dos consumidores por produtos prontos para consumo cresceu substancialmente na última década, incentivando o desenvolvimento de tecnologias que permitam sua fabricação com qualidade.

A transformação do alho (Allium sativum L.) em pasta pronta para consumo, estável à temperatura ambiente, tanto do ponto de vista microbiológico como a aparência, facilita a utilização desta horticola, que causa desconforto quando da sua manipulação, devido ao cheiro forte e característico causado pelos compostos organossulfurados, principalmente da alicina (dialil dissulfido) [9].

A principal perda de qualidade da pasta de alho é causada pelo escurecimento, que ocorre devido à ação da enzima polifenoloxidase sobre os compostos fenólicos, os quais são oxidados a ortoquinonas, as quais Recebido para publicação em 24/07/2002. Aceito para publicação em 23/04/2003 (000905)

${ }^{2}$ Instituto de Tecnologia de Alimentos - ITAL - Centro de Tecnologia de Hortifruticolas - Av. Brasil, 2880, Jd. Chapadão, Campinas, SP. - CEP13073-001-C.P.139-e-mail:sberbari@ital.org.br

${ }^{3}$ Instituto de Tecnologia de Alimentos - ITAL - Laboratório de Microbiologia Av. Brasil, 2880, Jd. Chapadão, Campinas, SP. - CEP-13073-001-C. P. 139. * A quem a correspondência deve ser enviada. polimerizam facilmente formando compostos escuros, ou seja, as melaninas [5].

O ácido cítrico é um acidulante versátil e muito utilizado pelas indústrias de alimentos, tendo como características a alta solubilidade, a ação seqüestrante de íns metálicos, que previne reações indesejáveis de oxidação de cor e aromas, segurança de manipulação, inocuidade do ponto de vista de saúde e baixa corrosividade das instalações industriais [6]. Desta forma, sua utilização se constitui em uma alternativa simples e segura para processamento industrial de pasta de alho.

Poucas são as informações bibliográficas disponiveis sobre processamento e conservação de pasta de alho, pois a maioria delas encontra-se na forma de patentes.

BERNHARDT \& DELAZARI [4] estudaram tratamentos prévios para facilitar o descascamento de dentes de alho de baixo valor comercial e a estabilidade da pasta de alho com adição de sal. Estes autores concluíram que um tratamento prévio em água a aproximadamente $80^{\circ} \mathrm{C}$ por 3 minutos, facilita a remoção da casca dos dentes de alho, e que a pasta de alho formulada com uma parte de sal para duas partes de alho conservou-se sem problemas durante nove meses de observação.

IRIGARAY \& CAPELANI [8] estudaram a conservação da pasta de alho por irradiação com raios gama por um 
periodo de quatro meses. Foram testados diferentes doses de irradiação variando de 0,1 a 10kGy e comparados com tratamentos quimicos tradicionais, que utilizam $0,5 \%$ de ácido cítrico e 0,04\% de anidrido sulfuroso. Os resultados mostraram que um tratamento de irradiação com 3kGy confere estabilidade microbiológica à pasta de alho.

\section{2 - MATERIAL E MÉTODOS}

\section{1 - Acidificação do alho in natura}

Na matéria-prima, alho argentino com seis meses de colheita, foi realizada uma análise de curva de acidificação para estabelecer a quantidade de ácido cítrico necessária para abaixar seu pH inicial para 4,0, conforme metodologia descrita por BERBARI \& PASCHOALINO [3]. O periodo de 6 meses após a colheita é o limite para utilização do alho, pois o bulbilhos apresentam-se dormentes, não tendo sido iniciada a germinação do dente, que causa alterações fisiológicas nos mesmos [9].

\section{2 - Processamento da pasta de alho}

O fluxograma constante da Figura 1 apresenta as etapas envolvidas no processamento da pasta de alho.

\section{Matéria-prima (dentes de alho in natura)}

$\downarrow$

Tratamento de imersão para facilitar o descascamento

$\downarrow$

Obtenção da pasta - "cutter"

$\downarrow$

Adição do ácido cítrico e do sorbato de potássio

$\downarrow$

Acondicionamento em vidros e potes plásticos

$\downarrow$

Desaeração parcial

$\downarrow$

Armazenamento à temperatura ambiente

FIGURA 1. Etapas envolvidas no processamento da pasta de alho.

O processamento da pasta de alho compreendeu às etapas de tratamento de imersão dos grãos em água a $80^{\circ} \mathrm{C}$ por 3 minutos para facilitar o descascamento [4] com auxilio de facas; trituração em equipamento do tipo "cutter", operando com velocidade baixa para a bacia e para as facas, por 50 segundos; adição do ácido cítrico $(2,1 \%)$, para evitar o escurecimento e de sorbato de potássio $(0,1 \%)$ para controlar o desenvolvimento microbiológico; acondicionamento em potes plásticos de polietileno de alta densidade (PEAD) e vidros, ambos com capacidade para $200 \mathrm{~g}$ de produto; desaeração parcial em câmara de vácuo; fechamento das embalagens plásticas por encaixe das tampas de policloreto de vinila (PVC) com o pote e das embalagens de vidro, com tampas metálicas de rosca; e armazenamento à temperatura ambiente. As embalagens utilizadas encontram-se disponiveis no mercado e são comumente utilizadas pelas indústrias de pequeno porte para acondicionar temperos em pasta.

\section{3 - Avaliação do produto final - pasta de alho}

\subsection{1 - Avaliação microbiológica}

Foram realizadas contagens de bactérias do tipo coliformes fecais, bactérias lácticas, bolores e leveduras segundo metodologia descrita por VANDERZANT \& SPLITTSTOESSER [12]. As análises foram realizadas ao zero e aos 90 dias de armazenamento.

\subsection{2 - Análises físicas - determinação objetiva da cor}

Foi realizada em colorimetro marca Minolta Chroma Meter CR - 300, sistema Hunter Lab, com resultados expressos em valor de L (luminosidade), a (negativo = verde, positivo $=$ vermelho $)$ e $\mathrm{b}($ positivo $=$ amarelo, nega tivo $=$ azul). Foi calculada a diferença total de cor $(\Delta \mathrm{E})$ de acordo com a equação:

$\Delta \mathrm{E}=\left[(\Delta \mathrm{L})^{2}+(\Delta \mathrm{a})^{2}+(\Delta \mathrm{b})^{2}\right]^{1 / 2}$

Onde: $\Delta$ é a diferença entre cada parâmetro de cor das amostras iniciais e das amostras armazenadas. As análises foram realizadas em triplicata a cada 15 dias durante os primeiros 45 dias e a cada 10 dias, durante os 30 dias finais. Os resultados obtidos foram avaliados através de análise de variância (ANOVA), Teste F e Teste de Tukey, utilizando-se o programa SAS(SAS Use's Guide: Version 6.11. Edition 1996, Institute Inc, n. C. USA).

\subsection{3 - Análises sensoriais}

Para avaliar sensorialmente a estabilidade da pasta de alho foram realizados testes de escala para os atributos de cor e odor a cada 15 dias, durante os primeiros 45 dias e a cada 10 dias, durante os 30 dias finais. Foi utilizada uma equipe de 12 provadores treinados para este tipo de teste. Os resultados obtidos foram avaliados através de análise de variância (ANOVA), Teste F e Teste de Tukey, utilizando-se o programa SAS(SAS Use's Guide: Version 6.11. Edition 1996, Institute Inc, n. C. USA). Foram utilizadas escalas verbais estruturadas com 7 pontos, por apresentarem especificidade suficiente para este teste, sendo que os termos "cor muito escura" e "cor muito clara", correspondiam respectivamente ao valores 1 e 7 , na avaliação da cor e os termos "odor muito estranho" e "odor característico", correspondiam respectivamente aos valores 1 e 7, na avaliação de odor. As amostras foram apresentadas aleatoriamente aos provadores em placas de vidro transparente, codificadas com números de três dígitos. Utilizou-se o delineamento experimental de blocos completos casualizados. As avaliações foram realizadas em cabines individuais com iluminação fluorescente e uniforme. 


\section{3 - RESULTADOS E DISCUSSÃO}

\section{1 - Curva de acidificação}

Os resultados da curva de acidificação do alho in natura apresentados na Figura 2 mostram que para abaixar o pH inicial do alho 6,24 para 4,00, foram necessários $2,10 \mathrm{~g}$ de ácido cítrico anidro para cada $100 \mathrm{~g}$ de alho descascado. O uso de conservadores químicos está relacionado com o pH do meio, pois a forma não-dissociada da molécula é que confere sua caracteristica antimicrobiana [2]. Os valores de pka, da maioria dos conservadores quimicos encontram-se na faixa de $\mathrm{pH}$ entre 3,0 e 5,0, portanto, a concentração da forma não dissociada aumenta com o aumento da acidez do alimento [2], daí a necessidade da acidificação dos produtos a serem submetidos a conservação química.

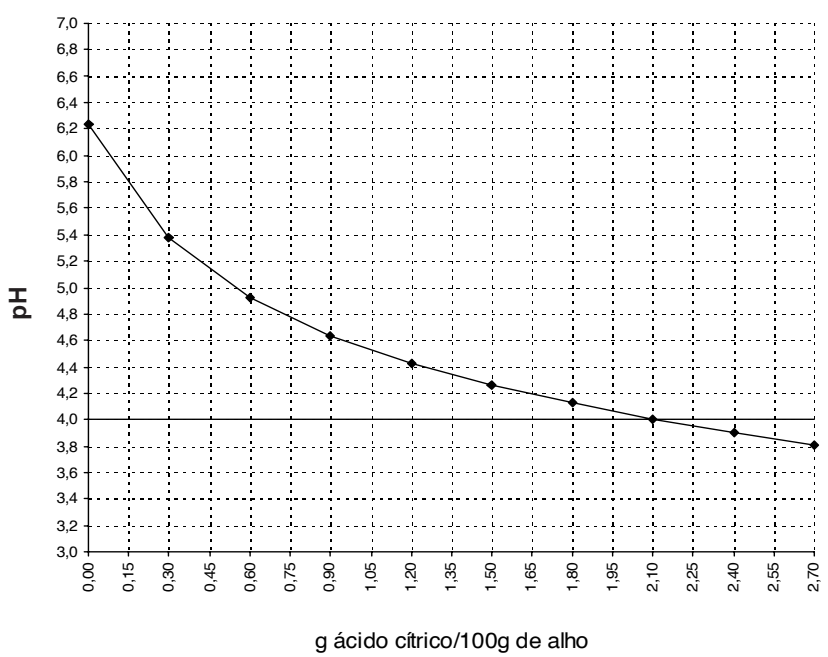

FIGURA 2. Curva de acidificação do alho in natura

\section{2 - Avaliação microbiológica}

A Tabela 1 apresenta os resultados da avaliação microbiológica realizada ao primeiro e aos 90 dias de armazenamento da pasta de alho. Do ponto de vista microbiológico, para todas as amostras estudadas, o produto manteve-se estável e com contagens de coliformes fecais, bactérias lácticas, bolores e leveduras abaixo do padrão exigido pela legislação brasileira, que é de $10^{4} \mathrm{UFC} / \mathrm{g}$ para produtos prontos para consumo [1]. A acidificação até pH 4,0 e a adição de sorbato de potássio, em conjunto com a atividade antimicrobiana dos compostos naturalmente presentes no alho controlaram o desenvolvimento microbiológico. Pesquisas realizadas in vivo e in vitro demonstraram que o alho possui dois principios ativos antimicrobianos distintos, a alicina e a garlicina, que possuem ação predominantemente bacteriostática, sendo eficazes tanto contra bactérias gram-positivas quanto gram-negativas [10]. Vale ressaltar que a desaeração não influenciou o desenvolvimento microbiológico do produto.
TABELA 1. Resultados da avaliação microbiológica.

\begin{tabular}{|c|c|c|c|c|}
\hline \multicolumn{5}{|c|}{ Época de Aval iação $-1^{\circ}$ dia } \\
\hline \multicolumn{5}{|c|}{ AMOSTRAS } \\
\hline Determinações & Vidro & $\begin{array}{c}\text { Vidro } \\
\text { com desaer ação } \\
\end{array}$ & Plástico & $\begin{array}{c}\text { Plástico } \\
\text { com desaer ação }\end{array}$ \\
\hline $\begin{array}{l}\text { Coliformes fecais } \\
(N M P / G)^{*}\end{array}$ & $<0,3$ & $<0,3$ & $<0,3$ & $<0,3$ \\
\hline $\begin{array}{l}\text { Bactérias lácticas } \\
(\mathrm{UFC} / \mathrm{G})^{\star \star}\end{array}$ & $<10$ & $<10$ & $<10$ & $<10$ \\
\hline $\begin{array}{l}\text { Bolores e leveduras } \\
\qquad(\mathrm{UFC} / \mathrm{G})^{\star \star}\end{array}$ & $<10^{2}$ & $<10^{2}$ & $<10^{2}$ & $<10^{2}$ \\
\hline \multicolumn{5}{|c|}{ Época de Avaliação - $90^{\circ}$ dia } \\
\hline \multicolumn{5}{|c|}{ AMOSTRAS } \\
\hline Determinaçōes & Vidro & $\begin{array}{c}\text { Vidro } \\
\text { com desaeração }\end{array}$ & Plástico & $\begin{array}{c}\text { Plástico } \\
\text { com desaeração }\end{array}$ \\
\hline $\begin{array}{l}\text { Coliformes fecais } \\
(N M P / G)^{*}\end{array}$ & $<0,3$ & $<0,3$ & $<0,3$ & $<0,3$ \\
\hline $\begin{array}{l}\text { Bactérias lácticas } \\
(\text { UFC/G })^{\star \star}\end{array}$ & $<10$ & $<10$ & $<10$ & $<10$ \\
\hline $\begin{array}{l}\text { Bolores e leveduras } \\
\qquad(\mathrm{UFC} / \mathrm{G})^{\star \star}\end{array}$ & $<10^{2}$ & $<10^{2}$ & $<10^{2}$ & $<10^{2}$ \\
\hline
\end{tabular}

$(\mathrm{NMP} / \mathrm{G})^{*}$ Número mais provável por grama $(\mathrm{UFC} / \mathrm{G})^{* *}$ Unidades Formadoras de Colônia por grama

\section{3 - Avaliação objetiva da cor}

A Tabela 2 apresenta os resultados da avaliação objetiva da cor das amostras com base nos parâmetros L, a e b.

TABELA 2. Resultados da avaliação objetiva da cor.

\begin{tabular}{|c|c|c|c|c|}
\hline \multirow[b]{2}{*}{ Period o de aval iação } & \multicolumn{4}{|c|}{ Parâmetro L - luminosidade } \\
\hline & vidro & $\begin{array}{l}\text { Vidro com } \\
\text { desaeração }\end{array}$ & plástico & $\begin{array}{l}\text { plástico com } \\
\text { desaeração }\end{array}$ \\
\hline $1^{a}$ (0 dia) & $67.81^{\mathrm{aA}}$ & $67.60^{\mathrm{aA}}$ & $67.42^{\mathrm{aA}}$ & $67.76^{\mathrm{aA}}$ \\
\hline $2^{\mathrm{a}}(15$ dias $)$ & $66.45^{\mathrm{bB}}$ & $67.33^{\mathrm{aA}}$ & $66.89^{\mathrm{a}, \mathrm{b} \mathrm{A}}$ & $67.18^{\mathrm{a}, \mathrm{bA}}$ \\
\hline $3^{\mathrm{a}}(30$ dias $)$ & $65.72^{\mathrm{a}, \mathrm{b} B, \mathrm{c}}$ & $65.98^{\mathrm{a}, \mathrm{b} B}$ & $66.41^{\mathrm{aA}, \mathrm{B}}$ & $65.51^{\mathrm{aB}}$ \\
\hline $4^{\mathrm{a}}(45$ dias $)$ & $65.45^{\mathrm{ac}}$ & $65.23^{\mathrm{ac}}$ & $65.41^{\mathrm{aB}, \mathrm{C}}$ & $65.43^{\mathrm{a} \mathrm{B}}$ \\
\hline $5^{\mathrm{a}}(60$ dias $)$ & $65.42^{\mathrm{a} C}$ & $65.06^{\mathrm{ac}}$ & $65.24^{\mathrm{aB}, \mathrm{C}}$ & $65.20^{\mathrm{aB}, \mathrm{C}}$ \\
\hline $6^{a}(70$ dias $)$ & $64.95^{\mathrm{a} C, \mathrm{D}}$ & $65.06^{\mathrm{ac}}$ & $65.00^{\mathrm{a} C, \mathrm{D}}$ & $65.23^{\mathrm{aB}, \mathrm{C}}$ \\
\hline $7^{\mathrm{a}}(80$ dias $)$ & $64.57^{\mathrm{aD}}$ & $64.61^{\mathrm{aC}}$ & $64.57^{\mathrm{a} C, \mathrm{D}}$ & $64.48^{\mathrm{a} C, \mathrm{D}}$ \\
\hline \multirow[t]{2}{*}{$8^{\mathrm{a}}(90$ dias $)$} & $63.50^{\mathrm{aE}}$ & $63.70^{\mathrm{aD}}$ & $63.87^{\mathrm{aD}}$ & $64.16^{\mathrm{aD}}$ \\
\hline & \multicolumn{4}{|c|}{ Parâmetro a (negativo = cor verde) } \\
\hline Period o de aval iação & vidro & $\begin{array}{l}\text { Vidro com } \\
\text { desaeração }\end{array}$ & plástico & $\begin{array}{l}\text { plástico com } \\
\text { desaeração }\end{array}$ \\
\hline $1^{a}$ (0 dia) & $-3.34^{\mathrm{aA}}$ & $-3.27^{\mathrm{aA}}$ & $-3.62^{\mathrm{aA}}$ & $-3.39^{\mathrm{aA}, \mathrm{B}}$ \\
\hline $2^{\mathrm{a}}(15$ dias $)$ & $-3.30^{\mathrm{aA}}$ & $-3.42^{\mathrm{aA}}$ & $-3.51^{\mathrm{aA}}$ & $-3.71^{\mathrm{aA}}$ \\
\hline $3^{\mathrm{a}}$ (30 dias) & $-3.03^{\mathrm{aA}, \mathrm{B}}$ & $-3.36^{\mathrm{a} A, \mathrm{~B}}$ & $-3.25^{\mathrm{aA}, \mathrm{B}}$ & $-2.92^{\mathrm{aB}, \mathrm{C}}$ \\
\hline $4^{\mathrm{a}}(45$ dias $)$ & $-2.81^{\mathrm{aB}}$ & $-2.42^{\mathrm{a} C, \mathrm{D}}$ & $-2.90^{\mathrm{a} B C}$ & $-2.77^{\mathrm{aD}, \mathrm{C}}$ \\
\hline $5^{\mathrm{a}}(60$ dias $)$ & $-2.66^{\mathrm{aB}, \mathrm{C}}$ & $-2.61^{\mathrm{aA}, \mathrm{B}}$ & $-2.47^{\mathrm{a} C, \mathrm{D}}$ & $-2.79^{a D, C}$ \\
\hline $6^{\mathrm{a}}(70$ dias $)$ & $-2.30^{\mathrm{a} C, \mathrm{D}}$ & $-2.29^{\mathrm{a} C, \mathrm{D}}$ & $-2.28^{\mathrm{a} D, E}$ & $-2.35^{\mathrm{a}, \mathrm{D}}$ \\
\hline $7^{\mathrm{a}}(80$ dias $)$ & $-1.91^{\mathrm{aD}, \mathrm{E}}$ & $-1.91^{\mathrm{aD}, \mathrm{E}}$ & $-2.11^{\mathrm{a} D \mathrm{D}}$ & $-2.06^{\mathrm{a}} \mathrm{EF}$ \\
\hline \multirow[t]{2}{*}{$8^{\mathrm{a}}(90$ dias $)$} & $-1.75^{\mathrm{aE}}$ & $-1.66^{\mathrm{aE}}$ & $-1.86^{\mathrm{aE}}$ & $-1.77^{\mathrm{a} F}$ \\
\hline & \multicolumn{4}{|c|}{ Parâmetro b ( positivo = cor amarela) } \\
\hline Períod o de avaliação & vidro & $\begin{array}{l}\text { Vidro com } \\
\text { desaeração }\end{array}$ & plástico & $\begin{array}{l}\text { plástico com } \\
\text { desaeração }\end{array}$ \\
\hline $1^{\text {a }}$ (0 dia) & $14.66^{\mathrm{a} C}$ & $16.67^{\mathrm{aE}}$ & $15.95^{\mathrm{a} E}$ & $16.23^{\mathrm{a} E}$ \\
\hline $2^{\mathrm{a}}(15$ dias $)$ & $19.62^{\mathrm{aB}}$ & $19.26^{\mathrm{a} D}$ & $19.69^{\mathrm{aD}}$ & $19.63^{\mathrm{aD}}$ \\
\hline $3^{\mathrm{a}}$ (30 dias) & $22.43^{\mathrm{a} A \mathrm{~B}}$ & $22.56^{\mathrm{aC}}$ & $22.98^{\mathrm{a} B, C}$ & $22.95^{\mathrm{aC}}$ \\
\hline $4^{\mathrm{a}}(45$ dias $)$ & $23.42^{\mathrm{a} A \mathrm{~B}}$ & $23.27^{\mathrm{a} B, \mathrm{C}}$ & $22.83^{\mathrm{aC}}$ & $23.48^{\mathrm{a} B, C}$ \\
\hline $5^{\mathrm{a}}(60$ dias $)$ & $23.40^{\mathrm{aA}}$ & $23.38^{\mathrm{a} B, \mathrm{C}}$ & $23.13^{\mathrm{a} A, \mathrm{~B}, \mathrm{C}}$ & $22.94^{\mathrm{aC}}$ \\
\hline $6^{\mathrm{a}}(70$ dias $)$ & $23.96^{\mathrm{aA}}$ & $23.67^{\mathrm{aA}, \mathrm{B}}$ & $24.18^{\mathrm{a} A, \mathrm{~B}, \mathrm{C}}$ & $23.75^{\mathrm{a} B, C}$ \\
\hline $7^{\mathrm{a}}(80$ dias $)$ & $24.32^{\mathrm{aA}}$ & $24.37^{\mathrm{AA}}$ & $24.19^{\mathrm{aA}, \mathrm{B}}$ & $24.20^{\mathrm{aA}, \mathrm{B}}$ \\
\hline $8^{\mathrm{a}}(90$ dias $)$ & $24.33^{\mathrm{aA}}$ & $24.08^{a, B}$ & $24.66^{\mathrm{aA}}$ & $25.08^{\mathrm{aA}}$ \\
\hline
\end{tabular}

Médias seguidas com a mesma letra minúscula na horizontal (Comparação entre amostras) e na vertical, com a mesma letra maiúscula (Comparação entre épocas de 
Através dos resultados da Tabela 2 pode-se verificar que durante o periodo de armazenamento, para todas as amostras estudadas, houve alteração significativa da cor da pasta de alho entre a primeira e a última avaliação (comparação vertical). Esta alteração é demonstrada pela diminuição da luminosidade (L) e da cor verde (a negativo), e aumento da cor amarela (b positivo), indicando o escurecimento das amostras.

As reações de escurecimento que ocorrem durante o armazenamento são aceleradas pela presença de fatores como luz e oxigênio. Neste sentido, embora as embalagens utilizadas apresentassem vantagens e desvantagens, ou seja, enquanto o vidro é impermeável a passagem de gases e vapores, o polietileno de alta densidade não apresenta alta barreira, mas apresenta maior resistência à passagem da luz que o vidro, que é transparente, além de apresentar maior custo[7], os resultados mostraram que para os parâmetros de cor avaliados, $\mathrm{L}$, a e b, os tipos de embalagens utilizadas e a desaeração, não influenciaram significativamente a alteração de cor da pasta de alho, ou seja, o escurecimento ocorreu em decorrência do tempo de armazenamento e não foi em função das condições de acondicionamento, conforme demonstram os resultados apresentados na Tabela 2 .

\section{4 - Avaliação sensorial}

Os resultados da avaliação subjetiva da cor das amostras de pasta de alho apresentados na Tabela 3 coincidem com os resultados obtidos pela avaliação objetiva, ou seja, a alteração significativa da cor foi também observada pela avaliação sensorial no decorrer do tempo de armazenamento, independente do tipo de acondicionamento utilizado. Segundo a equipe de provadores, a cor da pasta de alho variou entre os termos "cor característica", correspondente a primeira avaliação e "cor ligeiramente escura", correspondente a oitava época de avaliação. Estes resultados indicam que embora tenha ocorrido alteração significativa da cor, ao final dos três meses de armazenamento, as amostras não foram consideradas com "cor escura" pela equipe de provadores.

TABELA 3. Resultados da avaliação subjetiva da cor

\begin{tabular}{|c|c|c|c|c|}
\hline \multirow[t]{2}{*}{ Épocas de avaliação } & \multicolumn{4}{|c|}{ Amostras - médias das notas dos provadores } \\
\hline & vidro & $\begin{array}{l}\text { vidro com } \\
\text { desaeraçăo }\end{array}$ & plástico & $\begin{array}{l}\text { plástico com } \\
\text { desaeração }\end{array}$ \\
\hline $1^{\mathrm{a}}(\mathrm{O}$ dia $)$ & $3.89^{\mathrm{a} A}$ & $4.00^{\mathrm{a} A}$ & $4.22^{\mathrm{a}, \mathrm{A}}$ & $4.11^{\mathrm{a}, \mathrm{A}}$ \\
\hline $2^{\mathrm{a}}(15$ dias $)$ & $3.67^{\mathrm{aA}}$ & $3.78^{\mathrm{a}, \mathrm{AB}}$ & $3.67^{\mathrm{a}, \mathrm{ABC}}$ & $4.00^{\mathrm{a}, \mathrm{AB}}$ \\
\hline $3^{\mathrm{a}}$ (30 dias) & $3.44^{\mathrm{a}, \mathrm{AB}}$ & $3.55^{\mathrm{a}, \mathrm{AB}}$ & $3.78^{\mathrm{a}, \mathrm{AB}}$ & $3.67^{\mathrm{a}, \mathrm{AB}}$ \\
\hline $4^{\mathrm{a}}(45$ dias $)$ & $3.33^{\mathrm{a}, \mathrm{AB}}$ & $3.33^{\mathrm{a}, \mathrm{A} \mathrm{BC}}$ & $3.44^{\mathrm{a}, \mathrm{ABC}}$ & $3.22^{\mathrm{a}, A \mathrm{BC}}$ \\
\hline $5^{\mathrm{a}}(60$ dias $)$ & $3.33^{\mathrm{a}, \mathrm{AB}}$ & $3.11^{\mathrm{a}, \mathrm{BC}}$ & $3.44^{a, A B C}$ & $3.22^{\mathrm{a}, \mathrm{AB} \mathrm{BC}}$ \\
\hline $6^{a}(70$ dias $)$ & $3.44^{\mathrm{a}, \mathrm{AB}}$ & $3.11^{\mathrm{a}, \mathrm{BC}}$ & $3.22^{\mathrm{a}, \mathrm{BC}}$ & $3.22^{\mathrm{a}, \mathrm{ABC}}$ \\
\hline $7^{\mathrm{a}}(80$ dias $)$ & $3.22^{\mathrm{a}, \mathrm{AB}}$ & $3.22^{\mathrm{a}, \mathrm{C}}$ & $3.22^{\mathrm{a}, \mathrm{BC}}$ & $3.11^{\mathrm{a}, \mathrm{BC}}$ \\
\hline $8^{\mathrm{a}}(90$ dias $)$ & $3.00^{\mathrm{a}} \mathrm{B}$ & $2.67^{\mathrm{a}, \mathrm{c}}$ & $2.78^{\mathrm{a}, \mathrm{C}}$ & $2.67^{\mathrm{a}, \mathrm{C}}$ \\
\hline
\end{tabular}

Médias seguidas com a mesma letra minúscula na horizontal (Comparação entre amostras) e na vertical, com a mesma letra maiúscula (Comparação entre épocas de avaliação), não diferem significativamente ao nivel de erro de $5 \%$.

\section{5 - Relação entre cor objetiva e cor subjetiva}

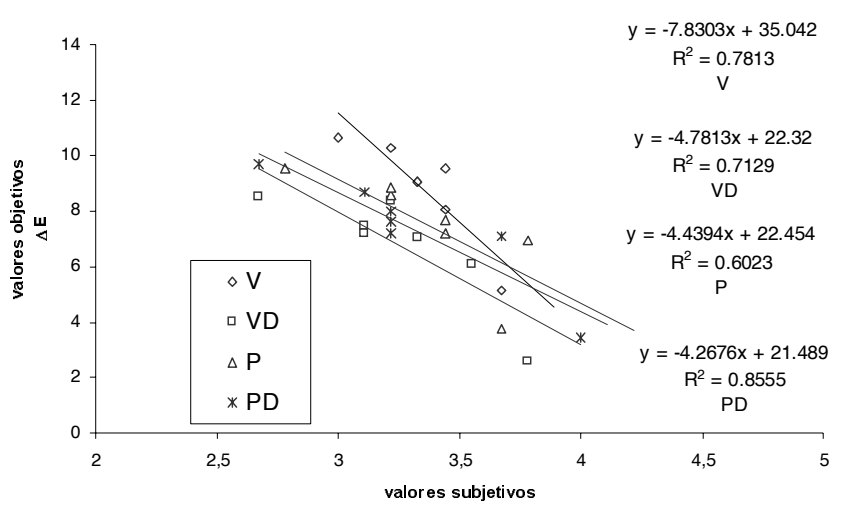

FIGURA 3. Correlação entre os resultados de diferença total de cor objetiva $(\Delta \mathrm{E})$ e os resultados da avaliação sensorial entre as amostras de pasta de alho. Codificação da amostras: V-vidro; VD - vidro com desaeração; P - plástico; PD - plástico com desaeração.

A Figura 3 apresenta a correlação obtida entre os resultados de diferença total de cor objetiva $(\Delta \mathrm{E})$ e os resultados da avaliação sensorial entre as amostras de pasta de alho, nos mesmos tempos de armazenamento. Os valores de (r) obtidos mostram uma boa correlação entre os resultados avaliados.

TABELA 4. Resultados da avaliação subjetiva do odor.

\begin{tabular}{|c|c|c|c|c|}
\hline \multirow[t]{2}{*}{ Épocas de avaliação } & \multicolumn{4}{|c|}{ Amostras - médias das notas dos provadores } \\
\hline & vidro & $\begin{array}{l}\text { vidro com } \\
\text { desaeraçäo }\end{array}$ & plástico & $\begin{array}{l}\text { plástico com } \\
\text { desaeraçäo }\end{array}$ \\
\hline $1^{a}$ (O dia) & $4.75^{\mathrm{a}, \mathrm{A}}$ & $4.62^{\mathrm{a}, \mathrm{A}}$ & $5.00^{\mathrm{a}, \mathrm{A}}$ & $5.12^{\mathrm{a}, \mathrm{A}}$ \\
\hline $2^{a}$ (15 dias) & $4.50^{\mathrm{a}, \mathrm{A}}$ & $4.38^{\mathrm{a}, \mathrm{A}}$ & $4.50^{\mathrm{a}, \mathrm{A}}$ & $4.37^{\mathrm{a}, \mathrm{A}}$ \\
\hline $3^{\mathrm{a}}$ (30 dias) & $4.37^{\mathrm{a}, \mathrm{A}}$ & $4.38^{\mathrm{a}, \mathrm{A}}$ & $4.62^{\mathrm{a}, \mathrm{A}}$ & $4.00^{\mathrm{a}, \mathrm{A}}$ \\
\hline $4^{\mathrm{a}}(45$ dias $)$ & $3.87^{\mathrm{a}, \mathrm{A}}$ & $4.12^{\mathrm{a}, \mathrm{A}}$ & $4.12^{\mathrm{a}, \mathrm{A}}$ & $3.75^{\mathrm{a}, \mathrm{A}}$ \\
\hline $5^{a}(60$ dias $)$ & $3.87^{\mathrm{a}, \mathrm{A}}$ & $4.00^{\mathrm{a}, \mathrm{A}}$ & $3.87^{\mathrm{a}, \mathrm{A}}$ & $4.12^{\mathrm{a}, \mathrm{A}}$ \\
\hline $6^{a}$ (70 dias) & $3.75^{\mathrm{a}, \mathrm{A}}$ & $4.12^{\mathrm{a}, \mathrm{A}}$ & $4.00^{\mathrm{a}, \mathrm{A}}$ & $3.87^{\mathrm{a}, \mathrm{A}}$ \\
\hline $7^{\mathrm{a}}$ (80 dias) & $3.87^{\mathrm{a}, \mathrm{A}}$ & $3.50^{\mathrm{a}, \mathrm{A}}$ & $4.00^{\mathrm{a}, \mathrm{A}}$ & $3.75^{\mathrm{a}, \mathrm{A}}$ \\
\hline $8^{\mathrm{a}}$ (90 dias) & $3.62^{\mathrm{a}, \mathrm{A}}$ & $3.25^{\mathrm{a}, \mathrm{A}}$ & $3.62^{\mathrm{a}, \mathrm{A}}$ & $3.50^{\mathrm{a}, \mathrm{A}}$ \\
\hline
\end{tabular}

Médias seguidas com a mesma letra minúscula na horizontal (Comparação entre amostras) e na vertical, com a mesma letra maiúscula (Comparação entre épocas de
avaliação), não diferem significativamente ao nível de erro de $5 \%$.

A Tabela 4 mostra os resultados da avaliação subjetiva do odor da pasta de alho. Durante o período de armazenamento não houve alteração significativa do odor das amostras. Quanto as condições de acondicionamento utilizadas, também para este atributo, não foi verificada diferença significativa entre as amostras.

\section{4 - CONCLUSÕES}

- A acidificação com ácido cítrico até $\mathrm{pH}=4,0$ foi eficiente para controlar o escurecimento das amostras de pasta de alho durante três meses de armazenamento a temperatura ambiente. No processamento industrial, para que este valor seja atingido de forma correta, há necessidade da determinação da curva de acidificação para cada lote de 
alho a ser processado, pois o comportamento de uma hortícola quando submetida à acidificação é influenciado por fatores como variedade, época de colheita, condições de cultivo e armazenamento pós-colheita.

- Os resultados indicam que a desaeração parcial da pasta de alho não influenciou na manutenção da sua coloração inicial.

- Quanto ao tipo de acondicionamento, de acordo com estes resultados, podem ser utilizados potes plásticos ou de vidro, pois ambos não influenciaram a manutenção da coloração inicial da pasta de alho.

- A partir destes resultados pode-se concluir também que as alterações de cor da pasta de alho ocorreram em função do tempo de armazenamento do produto.

\section{5 - REFERÊNCIAS BIBLIOGRÁFICAS}

[1] AGÊNCIA NACIONAL DE VIGILÂNCIA SANITÁRIA - ANVISA. Resolução RDC -12 de 2 de janeiro de 2001 - D.O.U. de 10/01/2001.

[2] ARAÚJO, J. M. A. Conservadores químicos em alimentos. Boletim da SBCTA, v. 24, n. 3/4, p. 192-210, 1990.

[3] BERBARI, S.A.G.; PASCHOALINO, J.E. Acidificação do palmito pupunha In: PASCHOALINO, J.E. Industrialização do palmito pupunha - Manual Técnico $\mathrm{N}^{\circ} 15$. Campinas: Instituto de Tecnologia de Alimentos, cap. 3, p. 23-30, 1997.
[4] BERNHARDT, L.W.; DELAZARI, I. Estudos preliminares sobre a produção e conservação de pasta de alho. Boletim do ITAL, v. 17, n. 1, p. 65-72, 1980.

[5] BOBBIO, P. A.; BOBBIO, F.O. Enzimas. In: BOBBIO, P. A.; BOBBIO, F.O. Introdução à química de alimentos. Campinas: Unicamp, cap. III 143-167, 1985.

[6] FERREIRA, A. F.S. Acidulantes na indústria de alimentos. I Simpósio sobre aditivos para alimentos. Campinas: ITAL, SP, 9-11 de set., 1987.

[7] GARcia, E. E. C., PADUla, M., SARANTÓPOUlos, C. I. G.L. Dados comparativos de propriedades de barreira. Embalagens plásticas: Propriedades de barreira. Campinas: ITAL, p. 8-40, 1989.

[8] IRIGARAY, J. L. \& CAPELANI, J. C. Etude comparative d"un procédé de conservation de pâte d"ail par irradiation gamma et par traitement chimique. Industries Alimentaires et Agricoles, v. 99, n. 11, p. 979-982, 1982.

[9] JUSWIAK, C. R. Alho: considerações sobre as alegações funcionais. Cadernos de Nutrição 18:13-21, 1999.

[10] SATURnino, H. M. Propriedades químicas e uso do alho. Informações Agropecuárias, Belo Horizonte, 4(48): 64-68, dez. 1978

[11] TAUSZIG, L. Controle e medição de cor e aparência na indústria de alimentos. In: MOURA, S.C.S.R. de; VISSOTTO, F.Z. Seminário sobre propriedades termofísicas aplicadas na garantia da qualidade dos alimentos. Campinas: Instituto de Tecnologia de Alimentos, 2000.

[12] VANDERZANT, C.; SPLITTSTOESSER, D. F. Compemdium of Methods for the Microbiological Examination of Foods, 3. Ed. Washington: American Public Health Association, 1992, 1219p. 